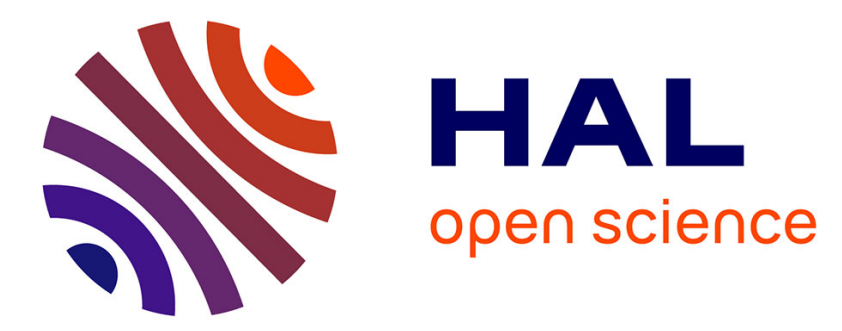

\title{
Stability of CdS Nanocrystals in Glass
}

\author{
T. Hayes, L. Lurio, J. Pant, P. Persans, H. Yükselici
}

\section{To cite this version:}

T. Hayes, L. Lurio, J. Pant, P. Persans, H. Yükselici. Stability of CdS Nanocrystals in Glass. Journal de Physique IV Proceedings, 1997, 7 (C2), pp.C2-1101-C2-1102. 10.1051/jp4:19972147 . jpa00255209

\section{HAL Id: jpa-00255209 https://hal.science/jpa-00255209}

Submitted on 1 Jan 1997

HAL is a multi-disciplinary open access archive for the deposit and dissemination of scientific research documents, whether they are published or not. The documents may come from teaching and research institutions in France or abroad, or from public or private research centers.
L'archive ouverte pluridisciplinaire HAL, est destinée au dépôt et à la diffusion de documents scientifiques de niveau recherche, publiés ou non, émanant des établissements d'enseignement et de recherche français ou étrangers, des laboratoires publics ou privés. 


\title{
Stability of CdS Nanocrystals in Glass
}

\author{
T.M. Hayes, L.B. Lurio, J. Pant, P.D. Persans and H.Yükselici \\ Physics Department, Rensselaer Polytechnic Institute, Troy NY 12180-3590, U.S.A.
}

\begin{abstract}
We have measured and analyzed optical absorption and $\mathrm{x}$-ray absorption spectra of CdS nanocrystals grown by solid-state reaction in a borosilicate glass, with average crystallite radii from 1.4 to $5 \mathrm{~nm}$. The first (Cd-S) and second (Cd-Cd) neighbor distances are within $0.2 \%$ of the bulk values in all cases. We establish an upper bound for the interfacial tension of $0.15 \mathrm{~N} / \mathrm{m}$. Such low interface tension suggests that glass-embedded nanocrystals are inherently more stable than bare or capped nanocrystals of the same size.
\end{abstract}

Cadmium chalcogenide clusters and nanocrystals are of fundamental interest for a variety of size-induced quantum effects and are technologically promising as nonlinear optical and electro-optical materials for communications and computing applications. They can be produced by precipitation from a liquid solution [1] and by solid-state reaction in glass [2]. The latter approach has the advantages that mixed chalcogenide pseudobinary alloys can result, giving more control over absorption edge placement, and that the resulting particles are well separated in a transparent medium.

The stability of a crystallite of a given size is determined by the relative importance of an energy per unit volume which favors crystal formation and an energy per unit surface area of the opposite sign. This leads to the concept of a minimum stable size, usually parametrized as a critical radius $R_{c}$. A large surface energy density destabilizes the smaller crystallites, lessening the potential benefits from quantum confinement. It also reduces the rate of crystallite nucleation, increases the likelihood of surface defects, and leads to depression of the melting point.

The energy per unit surface area, or interfacial tension, can be deduced from a measurement of the degree of lattice compression as a function of crystallite size. Such a measurement was carried out by Goldstein $e t$ al. [3] for CdS nanoparticles precipitated from a liquid. They used electron diffraction to measure the lattice constant and transmission electron microscopy imaging to estimate the particle size, deducing surface energies of $1.74 \mathrm{~N} / \mathrm{m}$ for particles capped with mercaptoacetic acid and $2.50 \mathrm{~N} / \mathrm{m}$ for bare particles. The particle radii ranged from $\sim 1.3$ to $\sim 3.3 \mathrm{~nm}$. These are very large surface energies, more than twice that for bulk CdS. Given the deleterious effects of large interfacial tension, it is important for the prospects for these materials to determine if such large values are an unavoidable property of nanocrystals.

We have carried out a study of interfacial tension of CdS nanocrystals grown by solid-state reaction in a borosilicate glass. Samples characterized by different particle sizes were prepared by isothermal heat treatment for selected times. The particle sizes and lattice contraction were measured using optical absorption and X-ray absorption (XAS) spectroscopies, respectively.

Produced by Schott Glass Technologies, the starting material was a glass consisting of $\mathrm{SiO}_{2}: \mathrm{B}_{2} \mathrm{O}_{3}: \mathrm{Na}_{2} \mathrm{O}: \mathrm{CaO}: \mathrm{K}_{2} \mathrm{O}: \mathrm{ZnO}$ in the ratios 61:20:8.5:6.2:3.6:0.4, as determined by electron microprobe, and doped with $\mathrm{Cd}$ and $\mathrm{S}$. As received, the glass had been homogenized in the melt, quenched, and heat treated to initiate nucleation. It was a pale yellow-green color in transmission. We subjected $35 \times 5 \times 2 \mathrm{~mm}$ slices of this starting material to isothermal heat treatment at $625^{\circ}$ to $750^{\circ} \mathrm{C}$ for intervals between 0.25 and $14 \mathrm{~h}$.

The optical absorption spectra of the resulting composites were measured between 2 and $4 \mathrm{eV}$ [2]. Representative spectra for a series of glasses heat treated at $625^{\circ} \mathrm{C}$ are shown in Figure 1. The glass as received, referred to as "unstruck," is characterized by a very gradual onset of absorption starting at $\sim 2.9 \mathrm{eV}$. The spectrum evolves monotonically with heat treatment at $625^{\circ} \mathrm{C}$ to one characterized by a well defined peak at $\sim 3.3 \mathrm{eV}(0.5 \mathrm{~h})$, consistent with an average particle diame ter $d \approx 3 \mathrm{~nm}$. Eventually $(14 \mathrm{~h}$ ), the spectrum is characterized by a relatively sharp edge beginning at $2.75 \mathrm{eV}$ (and no peak), consistent with $d>4 \mathrm{~nm}$. Treatment at higher temperatures can reduce the edge to $\sim 2.6 \mathrm{eV}$, as shown in Figure 1 . Note that

* Presently at Massachusetts Institute of Technology, Cambridge, MA, USA . 
the edge of bulk CdS is at $2.45 \mathrm{eV}$. The substantial residual "blue shift" of the well-annealed samples could be due to quantum confinement, but is more likely due to $\sim 20 \% \mathrm{Zn}$ substitution for $\mathrm{Cd}$ in the nanocrystals, which we have quantified from the Raman shift. Taking this into account, the radius of the predominant particles in each sample can be deduced from the edge positions.

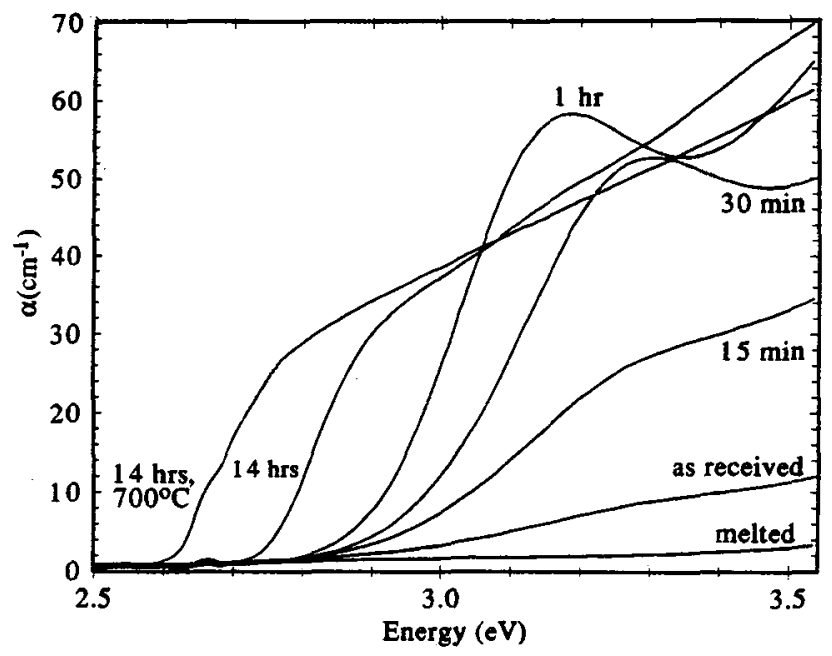

Figure 1: The optical absorptance $\alpha$ is shown as a function of photon energy for glasses held at $625^{\circ} \mathrm{C}$ for times as indicated. The leftmost trace corresponds to a sample held at $700^{\circ} \mathrm{C}$.

We measured the XAS spectra at the Cd K edge for these samples. We used fluorescence detection, but the Cd concentration in this low- $Z$ glass is sufficient to make transmission measurements competitive. The data were acquired at $20 \mathrm{~K}$ using a Si(220) "two-bounce" monochromator on beamline 4-2 at the Stanford Synchrotron Research Laboratory. Our optics yielded a measured resolution of $12 \mathrm{eV} \mathrm{FWHM}$ at the Cd K edge. The XAS spectra were reduced and analyzed using standard techniques [4]. Numerical analysis of the spectra using real-space signatures calculated by FEFF3 [5] or extracted from the CdS data yielded the following results.

In all the samples, both oxygen and sulfur were found as the nearest neighbors of $\mathrm{Cd}$. Due to the significant differences in the bonding of these elements to $\mathrm{Cd}$, we presume this to represent a mixture of sites coordinated with either six $\mathrm{O}$ or four $S$. In the unstruck sample, the nearest neighbors of $C d$ are consistent with a 50-50 mixture of (6)O and (4)S sites. After heat treatment for $14 \mathrm{~h}$, this becomes a 20-80 mixture, favoring $\mathrm{S}$. [Note that the environment is completely (4)S in CdS.]

At the same time, a small peak arises in the location of the second neighbor Cd peak in CdS, and with the same signature. The positions of the (first neighbor) sulfur and (second neighbor) $\mathrm{Cd}$ are found to be independent of size with error bars of \pm 0.2 and $0.5 \mathrm{pm}$ respectively. Following the analysis of Goldstein $e t$ al. [3], we can establish an upper bound for the interfacial tension of $0.15 \mathrm{~N} / \mathrm{m}$ for these samples. This is much lower than the interfacial tension measured earlier for nanocrystals precipitated from a liquid $[3,6]$, and suggests that the glass matrix relaxes about the nanocrystal/glass interface. It is very promising for the potential utility of these materials.

We thank Schott Glass Technologies for providing the unstruck doped glass. We gratefully acknowledge partial support of this research by NSF grants DMR-9006956 and 9104086 . The measurements were made at SSRL which is funded by the DOE Office of Basic Energy Sciences and the NIH Biotechnology Resource Program.

\section{References}

[1] M Steigerwald and L Brus, Ann Rev Mater Sci 19 (1989) 471

[2] H Yükselici, P D Persans, and T M Hayes, Phys Rev B 52 (1996) 11763

[3] A N Goldstein, C M Echer, and A P Alivisatos, Science 256 (1992) 1425

[4] For example, see T M Hayes and J B Boyce, in Solid State Physics 37, eds H Ehrenreich, F Seitz, and D Turnbull (Academic Press, New York, 1982), p 173

[5] I J Rehr, J Mustre de Leon, S I Zabinsky, and R C Albers, J Am Chem Soc 113 (1991) 5135

[6] S Tolbert and A P Alivisatos, J Chem Phys 102 (1995) 4642 